\title{
INSERÇÃO DAS EMPRESAS BRASILEIRAS E INDIANAS NO MOVIMENTO DE FUSÕES, AQUISIÇÕES NA INDÚSTRIA FARMACÊUTICA NO PERÍODO RECENTE (1997-2015)
}

\author{
Felipe Kamia $^{1}$ \\ Marco Vargas ${ }^{2}$ \\ Jorge Britto ${ }^{3}$
}

Área 5: Competências e capacitações das empresas

JEL: G34; L65; O57

Palavras chaves: Indústria farmacêutica; Fusões e Aquisições; Joint Ventures;

Competências.

\section{$\underline{\text { Resumo }}$}

As características individuais das firmas e o ambiente no qual estão inseridas são os fatores essenciais para explicar o crescimento das firmas. Uma das principais formas de realizar o processo de crescimento verificado pela literatura é a realização de operações patrimoniais, especialmente as fusões e aquisições. O presente trabalho tem como tema explorar o processo de operações patrimoniais envolvendo firmas do setor farmacêutico e biofarmacêutico no Brasil e Índia. Para isso iremos analisar os dados das operações de fusão e aquisição registradas pela base ORBIS entre os anos de 1997 e 2015, para explorar a hipótese de que as competências existentes nas firmas são um fator importante para definir sua forma de inserção nestas operações. $\mathrm{O}$ artigo contribui para a literatura ao utilizar uma base de dados para aprofundar tal discussão, indo além dos estudos de caso. Os resultados obtidos corroboram com as hipóteses apresentadas, ao mostrar que as empresas farmacêuticas indianas possuem um conjunto maior de competências e se inseriram de forma mais positiva no movimento de fusões e aquisições do que as empresas brasileiras.

\section{Abstract}

The individual characteristics of firms and the environment which they are inserted are essential factors to explain the growth of firms. One of the main ways to achieve this growth is the execution of mergers and acquisitions. This paper explores the process of mergers and acquisitions in the pharmaceutical markets on Brazil and India. We used the data of deals registered on ORBIS database between 1997 and 2015 in order to explore the hypothesis that existing competencies in firms are an important factor to define their insertion in these operations. The contribution of this article is the use of a database to deeper the discussion about this subject, going beyond the case studies. The findings support the hypothesis, showing that Indians firms have more competencies than Brazilian firms and have been inserted in the process of mergers and acquisition in better position than Brazilian firms.

\footnotetext{
${ }^{1}$ Mestrando em economia pelo PPGE/UFF. Contato: fkamia@id.uff..br.

2 Professor do departamento de economia da Universidade Federal Fluminense. E-mail: mvargas@economia.uff.br.

${ }^{3}$ Professor associado do departamento de economia da Universidade Federal Fluminense. E-mail: jbrit@terra.com.br
} 


\section{Introdução}

Os principais fatores que explicam as características do processo de crescimento das firmas são suas características individuais e o ambiente econômico em que estão inseridas. Uma das principais formas de realizar o processo de crescimento verificado pela literatura é a realização de operações patrimoniais, especialmente as fusões e aquisições. O trabalho assume que o conjunto de modificações no ambiente econômico que ocorreu na década de 90 alterou as estratégias de crescimento das firmas em direção à utilização cada vez maior das fusões e aquisição.

O presente trabalho busca explorar se o conjunto de competências internas às firmas é um fator importante para entender a forma de sua inserção nos processos de fusão e aquisição na indústria farmacêutica brasileira e indiana. Especificamente, buscamos identificar a existência de padrões na realização de fusões e aquisições, dado a existência prévia de competências nas firmas. A hipótese do trabalho é que o conjunto de competências determina a capacidade de absorção que possibilita a visualização e realização de oportunidades para o crescimento da firma via fusões e aquisições. A segunda hipótese é que as características do mercado (ambiente) indiano e brasileiro exercem influências sobre a realização de operações de fusão e aquisição nestes países.

Além desta breve introdução e da conclusão, o trabalho é composto por mais três seções. Na segunda seção, apresentamos brevemente a literatura sobre fusões e aquisições e o ambiente da indústria farmacêutica. Na terceira seção apresentamos a base de dados e a metodologia utilizada para identificar as competências econômicas das firmas. A quarta seção é dedicada à discussão dos dados encontrados e sua coerência com a literatura apresentada.

\section{$\underline{\text { Revisão da literatura }}$}

As operações de fusão e aquisição foram estudadas amplamente pela literatura. Entre os principais temas explorados, se destacam os trabalhos sobre os motivos para a realização das operações e seus efeitos nas firmas e mercados nos quais estão situadas. Apesar da grande diversidade de trabalhos, a principal constatação sobre a literatura que investiga as operações patrimoniais é sua indefinição. "Até o momento não existe nenhuma teoria geral sobre esse tipo de evento, mas um conjunto de explicações que se propõem a lhe conferir legitimidade, vinculadas a aspectos específicos de algumas das teorias das empresas” (Kloeckner, 1994). Destacam-se três abordagens teóricas sobre a firma que embasam as discussões sobre as operações de fusões e aquisições: a visão neoclássica (firma como maximizadora eficiente); a teoria da agência (dicotomia de interesses entre acionistas e executivos); e a visão penroseana da firma (firma como um conjunto de rotinas e competências).

Um dos poucos consensos observados nesta literatura é a constatação de que as fusões e aquisições ocorrem em "ondas”, ou seja, o movimento de fusões e aquisições tende a se concentrar em alguns espaços de tempo. Harford (2005) mostra que as ondas agregadas de fusões e aquisições são influenciadas, no nível macroeconômico, pelo nível de liquidez nos mercados de capitais. Entretanto, choques econômicos, regulatórios e tecnológicos se mostram fatores importantes quando observamos setores específicos.

Utilizando teorias baseadas na visão neoclássica da firma ou na teoria da agência, Kloeckner (1994) sistematiza quatro grupos de motivações para a realização de fusões e aquisições: motivos gerais; fusões horizontais ou verticais; co-seguro em fusões conglomeradas; e motivos gerenciais. Entre os motivos gerais, Kloeckner (1994) 
aponta: falhas de mercado, que gerariam expectativas assimétricas entre empresas compradoras e vendedoras; ou motivos econômico-financeiros, baseados na alocação eficiente dos recursos líquidos das empresas; busca por economia de custos; e assimetria entre os custos de reposição dos ativos e valor de mercado da empresa. Retomando o conceito da empresa racional e eficiente, o autor argumenta que as fusões horizontais e verticais podem ser realizadas para obter economias de escala, escopo ou para alcançar ganhos oligopolísticos (ganhos via efeitos anticompetitivos). As fusões e aquisições também podem ser orientadas para reduzir o risco de insolvências das empresas, quando uma empresa adquire outra com uma expectativa de fluxo de caixa pouco correlacionada com a da empresa adquirente. Finalmente, Kloeckner (1994) aponta mais duas razões gerenciais para a realização das operações de fusão e aquisição: o mercado de controle corporativo e a teoria do fluxo de caixa livre. O mercado de controle corporativo, baseado na visão de mercados eficientes, puniria empresas que não direcionassem sua gestão para a maximização do valor para o acionista. A perda do valor de mercado decorrente da punição do mercado abriria espaço para uma aquisição hostil que redirecionaria a gestão da empresa para a maximização do valor para os novos acionistas. Já a teoria do fluxo de caixa livre, baseada na teoria da agência, coloca que os executivos das empresas podem utilizar o fluxo de caixa livre da empresa para realizar aquisições em busca do crescimento da empresa.

Em “a teoria do crescimento da firma”, Edith Penrose atribui um capítulo específico para discutir as fusões e aquisições. As empresas certamente realizam fusões e aquisições para obter economias de escala e/ou escopo, obter vantagens financeiras, tributárias ou outras motivações apontadas anteriormente. Entretanto, "as fusões e aquisições são consequências normais e naturais da busca do lucro em uma economia competitiva onde a forma dominante de organização empresarial é a corporação e onde as leis permitam que uma corporação adquira outra” (Penrose, 2009, p136) ${ }^{4}$. Para a autora, se a firma visualizar a aquisição como a forma mais lucrativa para expandir, haverá uma tendência para que ela ocorra. O foco da análise penroseana recai sobre as seguintes questões: Por que a empresa alpha adquire beta em vez de desenvolver as atividades da beta internamente? Por que alpha acha lucrativo comprar beta?

Para entender as duas questões precisamos retomar alguns dos conceitos desenvolvidos pela escola neoschumpeteriana. Imersas em um ambiente econômico de informação incompleta e racionalidade limitada, as firmas desenvolvem rotinas, construindo capacidade e competências tácitas e agente-específicas que as diferenciam das demais concorrentes. A firma pode crescer internamente, de forma orgânica, através do aprendizado de novas competências. Entretanto, conforme identificou Malerba (1992), o processo de aprendizado é custoso, direcionado (targeted), está relacionado com fontes de conhecimento internas ou externas, é cumulativo e específico. Assim, a empresa alpha adquire a beta em vez de desenvolver as atividades de beta internamente porque o custo de oportunidade para o aprendizado das novas competências é maior do que o de realizar a aquisição. No entanto, por que o custo de aquisição de comprar beta é inferior ao de desenvolver as atividades de beta internamente?

Segundo a visão adotada, o preço de uma empresa seria equivalente à expectativa quanto ao valor presente líquido do fluxo de caixa futuro dos ativos da empresa (Penrose, 1959). Uma fusão ou aquisição somente ocorrerá se o preço que a empresa

4 "these processes are normal and natural consequences of profit-seeking in a competitive economy in which their corporation is the dominant form of business organization and the laws permits one corporation to acquire another" (Penrose, 2009) 
alpha esteja disposta a oferecer seja igual ou maior do que o preço mínimo requerido pela empresa beta. A teoria neoclássica atribuiu essa diferença em função a uma assimetria de expectativas geradas por falhas de mercado (criadas intencionalmente pelos agentes ou não). Segundo a visão penroseana da firma, a diferença nas expectativas é natural e reside na heterogeneidade natural existentes entre as firmas. As diferentes dotações de competências entre as firmas, que explicam suas heterogeneidades, implicariam que cada firma teria uma capacidade diferenciada de explorar um conjunto de ativos. Assim, seria natural a assimetria de expectativas sobre os fluxos de caixa futuro de diferentes combinações de competências que caracteriza cada firma.

O conjunto de competências que define uma firma é essencial para mensurar o potencial valor de explorar ativos de outras firmas. As firmas de um determinado setor normalmente carregam competências produtivas similares, espera-se que as fusões e aquisições predominem entre firmas que tenham compartilhem um conjunto comum de atividades. Iootty e Ebeling (2007) analisaram a coerência corporativa no processo de F\&A nos EUA na década de 90, com base em uma amostra representativa de 109 grandes empresas de setores diversos. Os autores concluíram que "ao diversificar suas atividades por meio de operações de F\&A, (a firma) seguiria um caminho relacionado no sentido de respeitar as restrições definidas pelas suas características tecnológicas e produtivas” (Iootty, Ebeling, 2007).

A execução de fusões e aquisições está condicionada às características da firma. "Embora a firma que escolha crescer via F\&A esteja à procura de recursos que ela não dispõe, (...) ela o faz com base nos recursos específicos que possui, o que certamente tende a condicionar a direção do crescimento” (Iootty, Ebeling, 2007). O caráter tácito e específico do conhecimento, das rotinas e das competências dificulta não só a identificação de novas oportunidades de obtenção de competências via F\&A, mas também a incorporação e exploração desses novos recursos. Portanto, o próprio processo de crescimento da firma via F\&A depende da capacidade de absorção da firma, gerando trajetórias únicas e que mantém o caráter path-dependence do crescimento.

A natureza do processo de aprendizado é uma das principais razões que motivam a decisão de uma firma adquirir outra em vez de desenvolver internamente as atividades. Entretanto, a própria natureza do aprendizado e o caráter tácito do conhecimento e das competências são fatores que dificultam o sucesso na realização destas operações. James (2002) realizou um estudo de caso baseado em três processos de F\&A na indústria farmacêutica e concluiu que o maior obstáculo para o sucesso dessas operações é a reconfiguração de recursos, rotinas e competências entre as firmas. Cloodt, Hagedoorn e Van Kranenburg (2006) realizaram um estudo sobre o impacto de fusões e aquisições em setores de alta intensidade tecnológica (incluindo a indústria farmacêutica) e concluíram que F\&A não tecnológicas não possibilitam maior aprendizado tecnológico e tem efeito negativo no desempenho inovativo das firmas. Em relação às operações ditas tecnológicas os autores concluíram que a aquisição da base de conhecimento da firma adquirida não implicava aumento na escala e escopo, bem como no aumento da base tecnológica da firma compradora; que o tamanho relativo da base de conhecimento incorporada tem uma relação negativa com performance em inovação; e que a similaridade na base de conhecimento da firma adquirida tem uma relação não linear (formato de U) com o desempenho inovativo da firma. Em conclusão, a partir de uma visão da firma baseada em recursos, abordagem da administração que se aproxima da visão da firma neoschumpeteriana, os autores chegaram à conclusão que as 
fusões e aquisições só melhoram o desempenho inovativo das firmas quando a base de conhecimento adquirida não é muito próxima nem muito dissimilar e quando as bases de conhecimento diferem em extensão relativa. Estas dificuldades estão refletidas em boa parte dos trabalhos empíricos realizados para tentar mensurar o desempenho das fusões e aquisiç̧ões.

Duas contribuições pertinentes a lucratividade das empresas após a realização das fusões e aquisições aparecem com destaque na literatura. A partir da teoria da agência, que explora a contradição entre os interesses de shareholders e executivos, Jensen e Ruback (1983) apontam que as fusões e aquisições seriam uma forma do mercado de controle corporativo alinhar os interesses dos executivos aos dos acionistas. Assim, empresas que não objetivassem a maximização do valor para os acionais seriam penalizadas pelo crivo do mercado, apresentando redução em seu valor, se tornando alvos fáceis para uma aquisição externa. Com a aquisição e posterior redirecionamento dos objetivos da empresa com os dos novos acionistas o seu valor de mercado apresentaria recuperação. Como consequência, as operações de fusões e aquisições bem-sucedidas gerariam ganhos extraordinários para as empresas adquiridas. Como seu estudo focava no mercado de controle corporativo, analisava empresas com baixo desempenho econômico nos períodos anteriores ao processo de F\&A. Como as operações não resultavam em ganhos de poder de mercado, os autores concluem que a geração de valor nessas empresas se dava pelo aumento da eficiência e exploração de sinergias possibilitadas pela integração. De forma contrária, Ravenscraft e Scherer (1987) encontram evidências de que as empresas adquiridas nos processos de F\&A detinham lucratividade acima da média para seus setores antes da ocorrência destes processos e que a lucratividade das firmas apresenta queda após a conclusão do processo. Não obstante, as F\&A permitiam ganhos expressivos para os acionistas das empresas compradoras e adquiridas, via ganhos especulativos possibilitados pela assimetria de informação existente.

A literatura em relação aos resultados das operações de fusões e aquisições sobre a produtividade também é contraditória. Koenig e Mezick (2004) concluem que, em comparação às empresas que não passaram por um processo de F\&A e em relação ao conjunto total das empresas, as firmas que experimentaram esse processo apresentaram ganhos de produtividade. Lamattina (2013) e Comanor e Scherer (2013) apresentam uma perspectiva oposta, identificando um impacto negativo para a produtividade da P\&D para as empresas que passaram por fusões ou aquisições. O impacto das operações patrimoniais sobre a concentração industrial também é controverso (Koshiyama e Martins, 2008). Apesar da ideia de que as fusões e aquisições tendem a aumentar a concentração industrial, não há consenso sobre o tamanho desta influência.

A utilização de metodologias e bases de dados distintas impede a comparação direta entre as pesquisas, mas as conclusões divergentes expõem a indefinição ainda existente neste debate. A dificuldade na obtenção de um consenso decorre, em parte, da dificuldade em obter dados que mostrem de forma satisfatória o impacto destas operações nas empresas que a realizaram. Em outras palavras, existe uma grande dificuldade em isolar o impacto destas operações patrimoniais nas firmas.

Os principais fatores que condicionam o processo de crescimento das firmas são as características individuais de cada firma e o ambiente no qual estão inseridas (Penrose, 1959; Dosi e Teece, 1998). A questão referente à heterogeneidade natural entre as firmas e sua consequência para as fusões e aquisições foi apresentada na seção anterior. $\mathrm{O}$ segundo fator, que trata do ambiente econômico no qual estas firmas estão inseridas, é descrito a seguir. 
A estrutura concorrencial da indústria farmacêutica é o oligopólio diferenciado baseado em ciência (Vargas, 2015). A diferenciação de produtos é pautada pelo esforço de pesquisa e desenvolvimento e pelo marketing. A concorrência se dá em segmentos de mercados específicos, dado a reduzida (muitas vezes ausente) substitubilidade entre produtos de diferentes classes terapêuticas (Bastos, 2005). O lançamento de produtos novos ou melhorados constitui elemento central no padrão de competição da indústria, possibilitado pela inovação tecnológica, exigindo elevados investimentos em P\&D (Bastos, 2005). Em 2014, as firmas do setor investiram cerca de 18\% do faturamento (US\$ 141,6 bilhões), valor próximo à média observada nos 10 anos anteriores (Evaluate Pharma 2015). Dada a proximidade do processo inovativo com o avanço científico e a elevada codificação do conhecimento no setor, a principal forma de apropriação da indústria é o uso de patentes (Capanema, 2006).

A estrutura competitiva da indústria farmacêutica apresentou uma mudança significativa a partir da década de 90 . O avanço científico na área biotecnológica em conjunto com o rápido progresso nas TICs alterou o processo de busca na indústria, criando novas oportunidades tecnológicas. Ao mesmo tempo, no entanto, provocaram a elevação dos custos de P\&D. Diversas mudanças regulatórias impactaram as condições de apropriabilidade e a lucratividade do setor. A expiração de patentes sobre medicamentos altamente lucrativos (patent cliff) afetou a expectativa de rentabilidade de diversas empresas, ao mesmo tempo em que estimulou estratégias relacionadas à produção e comercialização de genéricos. O acordo TRIPS (agreement on trade-related aspects of intelectual property rights) buscou homogeneizar os direitos de propriedade intelectual sobre medicamentos, estimulando a internacionalização das empresas de mercados desenvolvidos para os países em desenvolvimento. Ao mesmo tempo, as diferentes formas de aceitação destas regras impactaram a inserção e desenvolvimento das empresas nacionais nos mercados nacionais e externos. Por fim, o controle de preços dos medicamentos e mudanças nas regras para aprovação de novas drogas também alteraram as condições de lucratividade e apropriabilidade do setor (citar).

As empresas do setor farmacêutico utilizaram diversas estratégias para lidar com os desafios citados: elas fortaleceram suas estratégias de gestão, conciliando a descentralização da estrutura produtiva e a centralização do poder decisório; diversificaram sua área de atuação através da produção de medicamentos genéricos e sem necessidade de prescrição médica; ampliaram a atuação para mercados externos (especialmente a atuação das empresas de países desenvolvidos em países em desenvolvimento); buscaram economias de escala e escopo na produção, P\&D, marketing e distribuição (Vargas, 2015). Parte significativa dessas estratégias passou pela realização de fusões e aquisições ou a formação de joint ventures.

O avanço da biotecnologia possibilitou a exploração de novos mercados para a indústria farmacêutica. Segundo projeções da Evaluate Pharma (2015), a venda de drogas biotecnológicas aumentou sua participação no faturamento da indústria farmacêutica global de 14\% para 23\% de 2006 até 2014. Essa participação deve aumentar para 27\% até 2020. Entretanto, boa parte do conhecimento necessário para o domínio dessas competências não estava presente na indústria farmacêutica de base química. Como o aprendizado de competências é uma atividade custosa, a aquisição de empresas de base biotecnológica deve mostrar-se relevante.

A busca por mercados emergentes também deve ser observada no conjunto de fusões e aquisições, dado a elevação da renda dos países em desenvolvimento observada nas últimas décadas. O mercado farmacêutico brasileiro foi estimado em US\$ 28,1 bi em 2015 e deve alcançar entre US\$ 34-44 bi em 2020 (IMS, 2015). O mercado indiano 
foi estimado em US\$ 12,1 bi em 2015, com previsão de crescimento para US\$ 13-19 bi em 2020 (IMS, 2015).

A comparação do desenvolvimento dos mercados farmacêuticos da Índia e Brasil já foi realizada na literatura por alguns autores. Guennif e Ramani (2012) compararam o processo de catching-up dos dois países a partir da segunda guerra mundial, a partir do conceito dos sistemas nacionais de inovação. Ambos os países apresentarem diversos atributos em comum: um período considerável com regimes de propriedade intelectual que permitiam o uso de estratégias de engenharia reversa; grande mercado interno; e um subsistema de educação e pesquisa capacitado na área farmacêutica. Entretanto, enquanto a indústria farmacêutica indiana foi capaz de acumular competências produtivas, inovativas e regulatórias, a indústria farmacêutica brasileira não obteve mesmo sucesso, se restringindo salvo exceções, apenas à capacidade de formular produtos a partir de insumos farmacêuticos importados. Uma das consequências observadas pelos autores, muito relevante para esse trabalho exploratório, foi a inserção diferenciada das empresas destes países em operações patrimoniais e alianças estratégicas. Na Índia, as empresas indianas buscaram parcerias com empresas de países desenvolvidos para absorção de conhecimento e tecnologia. Além disso, o acúmulo de competências permitiu que estas empresas fossem capazes de enxergar janelas de oportunidade foras do país (ex: inserção de empresas indianas para explorar o mercado de genéricos brasileiro). Ao mesmo tempo, as empresas indianas passaram a se tornar mais atrativas para as grandes empresas farmacêuticas, que passaram a realizar grandes operações de aquisição no país no final da década de 2000. No Brasil, onde o acúmulo de competências foi muito inferior, o movimento de fusões e aquisições teria sido muito menor.

\section{Metodologia}

Os dados utilizados no estudo foram extraídos da base ORBIS, selecionando operações patrimoniais envolvendo empresas dos setores de biotecnologia, farmácia e ciências da vida. A amostra inicial continha informações sobre operações patrimoniais concluídas (inclusive as assumidas como concluídas) entre 1997 a 2015, com informações sobre a operação e as empresas envolvidas. As informações sobre a operação utilizadas foram o tipo de negociação; data de anúncio e de conclusão da operação; e o valor do negócio e da empresa alvo envolvida. As informações sobre a empresa obtidas foram a identificação das empresas envolvidas em cada negócio (compradora e alvo); o código de atividade principal e os demais códigos de atividade das empresas envolvidas na operação (NAICS, 2012); e a nacionalidade das empresas.

A análise se restringiu às operações de fusões, aquisições (inclusive minoritárias) e formação de joint ventures que envolvessem ao menos uma empresa do setor farmacêutico ou biofarmacêutico. Uma firma era considerada farmacêutica ou biofarmacêutica se apresentasse algum dos códigos relacionados ao setor farmacêutico ou biotecnológico como principal código de atividade. Após o tratamento, a base resultante apresentou 23.929 operações, sendo 23.174 operações de aquisição, 671 joint ventures e 84 fusões.

Com base nos setores de atividades das empresas, elaboramos indicadores para revelar a existência de competências específicas nas firmas. Foram identificadas competências relacionadas à manufatura de medicamentos (exceto os biológicos), aos produtos biológicos, à pesquisa e desenvolvimento e a distribuição de medicamentos. 
Adicionalmente foram identificadas as empresas financeiras que participaram do processo. ${ }^{5}$

O trabalho busca explorar a relação entre a existência prévia de competências e o conjunto de competências que a empresa acessa via fusões e aquisições ou pela formação de joint ventures. Para isso, cruzamos as informações sobre as operações patrimoniais com os indicadores de competências tecnológicas.

\section{$\underline{\text { Resultados }}$}

Segundo os dados obtidos junto a Orbis, percebe-se um número crescente de operações patrimoniais de 1997 a 2011, com redução no número de operações a partir daí. Entretanto, apesar do número de operações ter apresentado redução no começo dessa década, o valor total destas operações apresentou elevação. Em 1997 foram realizadas 145 operações de fusão, aquisição ou joint ventures, com um volume financeiro de US\$ 35 bilhões. Em 2000, 2005, 2010 e 2015, o número de operações saltou para 671, 2047, 2354 e 2480, respectivamente. O volume das operações nestes anos somou, respectivamente, \$222, \$136, \$140 e \$323 bilhões de dólares.

A partir da lista dos principais códigos de atividade NAICS 2012 construímos um indicador para classificar as empresas como farmacêuticas, financeiras ou de outros setores não financeiros. As empresas farmacêuticas ou biofarmacêuticas eram as que possuíam como principal código de atividade os códigos relacionados à manufatura; distribuição de medicamentos; ou pesquisa e desenvolvimento de produtos químicos e biotecnológicos (ver tabela completa no anexo 1). As empresas financeiras eram aquelas que possuíam as atividades de código 52 a dois dígitos da NAICS 2012 e o código 551111 (Holding de bancos). As demais empresas foram classificadas como de outros setores não financeiros.

Gráfico 1: Operações patrimoniais - setor farmacêutico e biotecnológico (1997-2015)

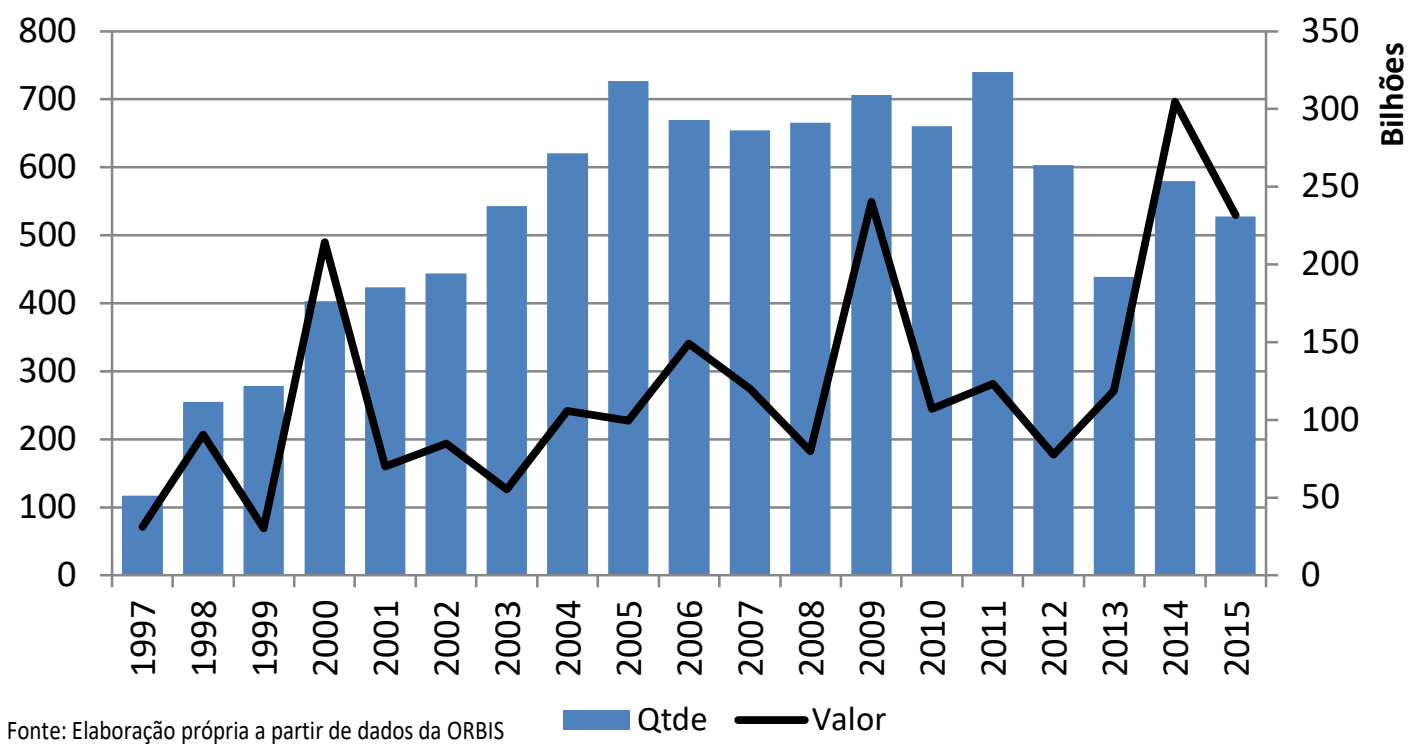

Conforme a tabela 1, 36\% das operações patrimoniais apresentavam um comprador do setor farmacêutico ou biofarmacêutico. As empresas do setor financeiro foram responsáveis por 32\% das aquisições (em especial, fundos de venture capital) e o restante das operações (32\%) tinham como compradoras empresas de outros setores.

\footnotetext{
5 A lista com os códigos de atividade utilizados para construir os indicadores está no anexo 1, ao
} final do artigo. 
Apesar da distribuição das operações serem similares, o valor médio das operações cujo adquirente era do setor farmacêutico foi de US\$ 427 milhões. Esse valor é muito superior aos observados nas compras lideradas por empresas financeiras ou de outros grupos não financeiros, cujos valores médios foram de US\$ 53 milhões e US\$ 37 milhões. É importante notar que a mediana das operações lideradas por empresas farmacêuticas (US\$ 15 milhões) também é superior que as medianas das operações cujo comprador era do setor financeiro (US\$ 4 milhões) ou de outros setores não financeiros (US\$ 8 milhões).

Tabela 1 - Participação dos setores no total de negócios

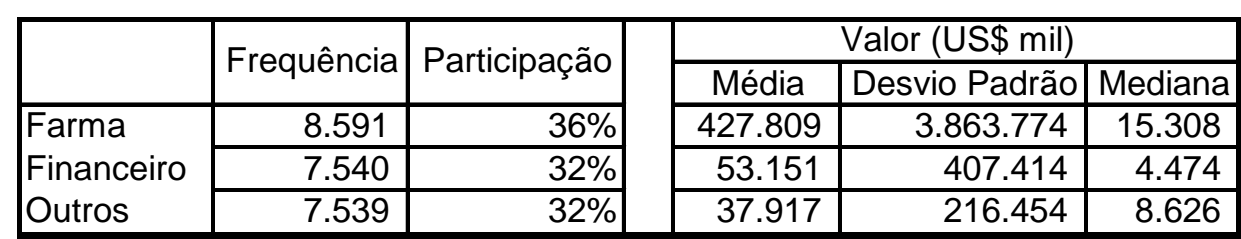

Fonte: Elaboração própria a partir dos dados da Orbis (2016)

Apesar das operações terem se distribuídos de forma relativamente uniforme entre as compradoras farmacêuticas e biotecnológicas, financeiras e demais empresas, a forma de execução dessas operações difere significativamente. Enquanto a principal forma de execução das operações patrimoniais para as empresas do setor farmacêutico é a aquisição majoritária, a principal forma de execução para as empresas do setor financeiro e outras empresas são as aquisições minoritárias. A formação de joint ventures e as fusões também se concentram nos casos onde a empresa compradora é farmacêutica ou biofarmacêutica.

\section{Gráfico 2: Distribuição setorial das operações patrimoniais}

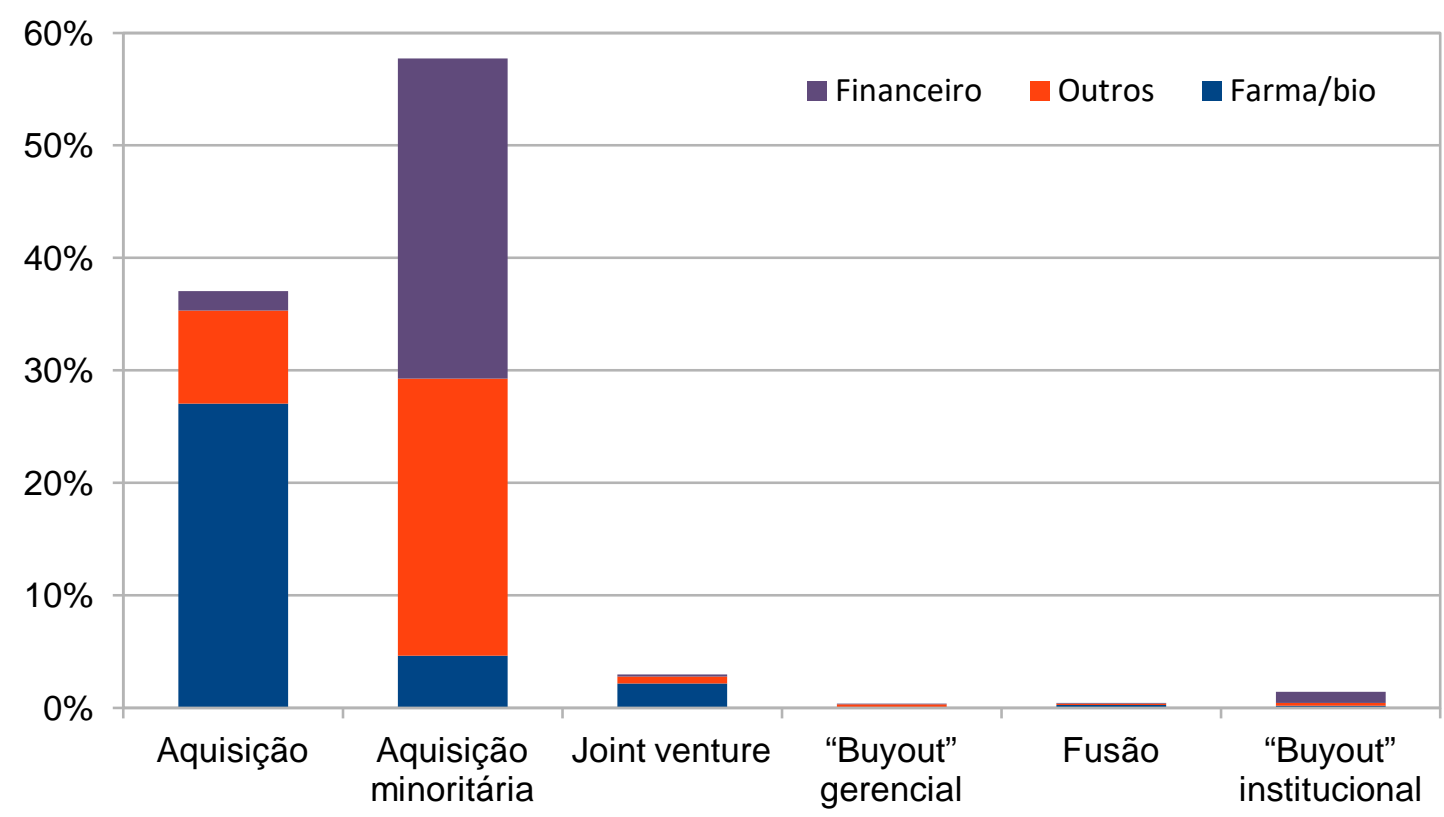

A constatação de que as operações cujos compradores eram do setor financeiro e de outros setores não-financeiros apresentam valor médio inferior que o das operações lideradas por empresas farmacêuticas está em consonância com o gráfico sobre a distribuição das operações patrimoniais por tipo de negócio. As operações cujos compradores eram do setor farmacêutico estão concentradas principalmente nas aquisições totais, enquanto as empresas financeiras e de outros setores não financeiros 
concentram suas operações em aquisições minoritárias. Uma das explicações para esse tipo de comportamento seria um elevado volume de operações lideradas por empresas financeiras para financiar startups tecnológicas.

O gráfico 3 apresenta a relevância do conjunto de competências das firmas alvo de acordo com a qualificação do comprador (linhas) ${ }^{6}$. Entretanto, como a base se restringe às operações patrimoniais envolvendo ao menos uma empresa do setor farmacêutico ou biofarmacêutico, geramos um viés na amostra. Não é possível verificar a importância das operações comandadas por empresas não farmacêuticas em direção ao setor farmacêutico em relação ao total das operações comandadas por estas empresas. Entretanto, podemos compreender qual a importância das operações direcionadas às distintas atividades que compõe o setor farmacêutico.

Segundo as informações da base, 95\% das operações cujos compradores eram do setor financeiro apresentavam competências em manufatura (exceto bio), 71\% das operações eram direcionadas a alvos com competências em $P \& D$ e 38,5\% das operações foram em direção a alvos com competências em biotecnologia. Apesar dos dados referentes ao setor financeiro apresentarem um viés que não pode ser ignorado, a elevada participação de operações cujo alvo detinha competências em bio ou em P\&D em relação aos outros grupos reforça a hipótese de que as empresas financeiras estejam em busca de oportunidades de investimento em startups tecnológicas.

\section{Gráfico 3: $O$ que as adquirentes estão comprando?}

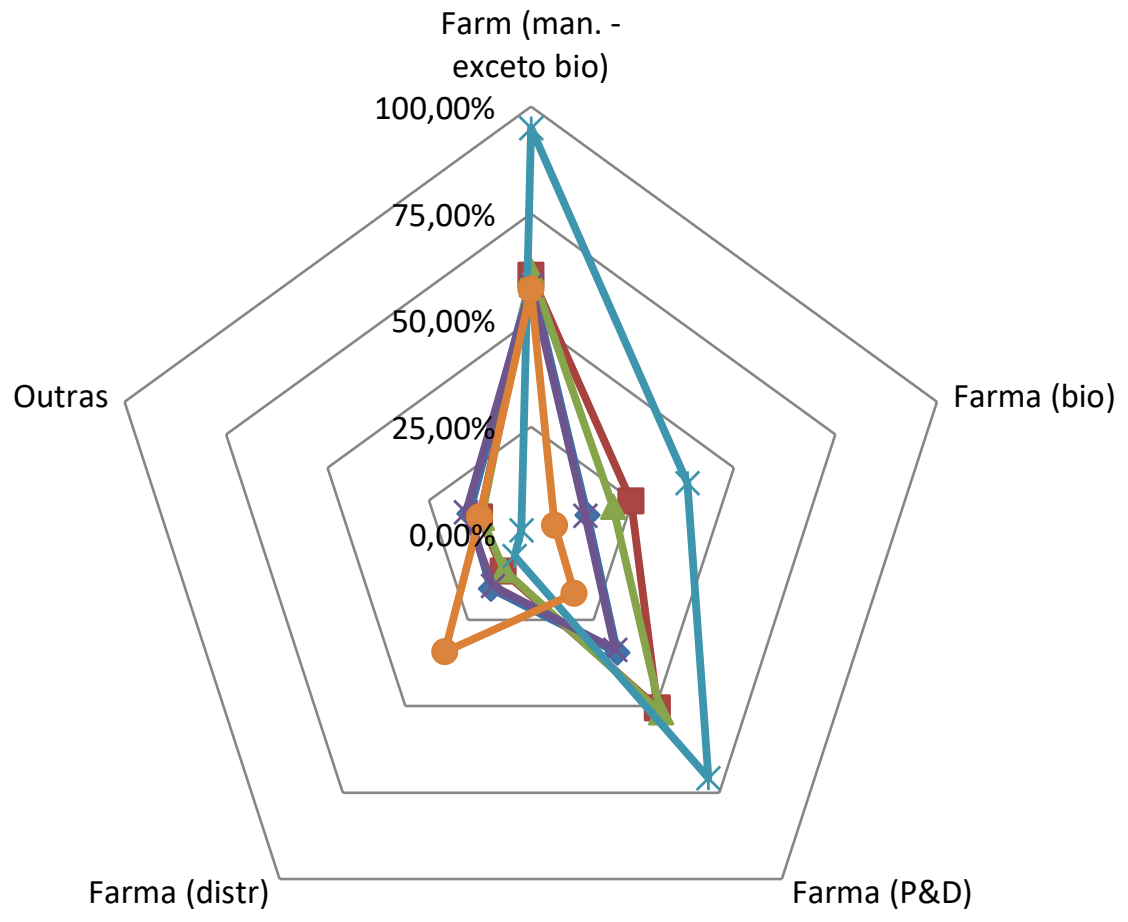

\footnotetext{
Comprador: Farma (amplo)

-Comprador: Farma (P\&D)

*Comprador: Financeiras*
}

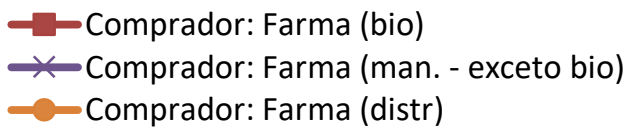

Fonte: Elaboração própria a partir dos dados da Orbis (2016)

\footnotetext{
${ }^{6}$ A identificação dos códigos de atividade associada a cada conjunto de competências e a cada grupo de firmas está listada em anexo no final do artigo.
} 
Cerca de $60 \%$ das operações realizadas por empresas do setor farmacêutico em sentido amplo foram direcionadas a empresas que possuíam competências na manufatura de produtos farmacêuticos, com exceção de produtos biológicos. Este dado se reflete na análise desagregada, que mostra um percentual similar para as empresas que possuem competências somente na manufatura (com exceção aos produtos biológicos), na pesquisa e desenvolvimento, em biofármacos e na distribuição de medicamentos.

Entretanto, algumas diferenças aparecem quando o alvo possui competências relacionadas aos biofármacos, à pesquisa e desenvolvimento e a distribuição de medicamentos. Entre as operações realizadas por empresas que possuíam competências em P\&D, 52\% foram direcionadas a alvos com competências nesse mesmo setor. As empresas que detinham competências em biofármacos, manufatura e distribuição direcionaram respectivamente $50 \%^{7}$, $33 \%$ e $17 \%$ de suas operações a alvos com competências em biofármacos. O mesmo padrão se repete na análise de outros grupos de competências. Desconsiderando as aquisições comandadas por empresas financeiras, o grupo que realizou, proporcionalmente, o maior número de operações com empresas que possuíam competências em biofármacos e na distribuição de medicamentos foi o que detinham aquelas competências. Os dados não são suficientes para afirmarem a hipótese de que o conjunto de competências é um fator determinante na capacidade das empresas em visualizarem e realizarem oportunidades de fusão, aquisição ou alianças estratégicas. Entretanto, parecem corroborar com a hipótese, sugerindo que os estudos explorando essa hipótese devem ser aprofundados.

O gráfico 4 traz informações para a qualificação do alvo por sua nacionalidade, de forma explorar a hipótese secundária de que o ambiente econômico específico aos países também é um determinante importante para a realização de fusões, aquisições e formação de joint ventures. O gráfico mede o percentual de alvos que possuem competências na manufatura, $\mathrm{P} \& \mathrm{D}$, biotecnologia, distribuição e outras atividades. Os dados mostram que as operações cujo alvo possui competências em manufatura (exceto produtos biológicos) eram mais frequentes no Brasil (65\% das operações) e na Índia (69\%) do que no resto do mundo (59\%). Em contraposição, as operações em direção a alvos com competências identificadas em pesquisa e desenvolvimento (35\%) e biotecnologia (14\%) são mais comuns em outros países do que na Índia (20\% em P\&D e 12\% em bio) e Brasil (9\% e 4\%). As operações com direção a alvo com competências na distribuição de medicamentos também aparecem com maior destaque no Brasil (22\%) do que na Índia (17\%) e no resto do mundo (16\%). Os dados indicam que as operações patrimoniais direcionadas ao Brasil estão mais relacionadas ao acesso do mercado interno. Este mesmo padrão se repete na Índia, mas com maior relevância das operações envolvendo alvos com competências em pesquisa e desenvolvimento e biotecnologia. Isso indica que outras motivações para a realização das operações patrimoniais podem estar em vigência, como a busca de competências tecnológicas e biotecnológicas por compradores estrangeiros.

\footnotetext{
Os grupos relacionados às competências em biofármacos e P\&D compartilham um código de atividade em comum (541711 - P\&D em biotecnologia), o que explica a proximidade nos resultados verificados para estes grupos.
} 


\section{Gráfico 4: Qualificação do alvo pela nacionalidade do alvo}

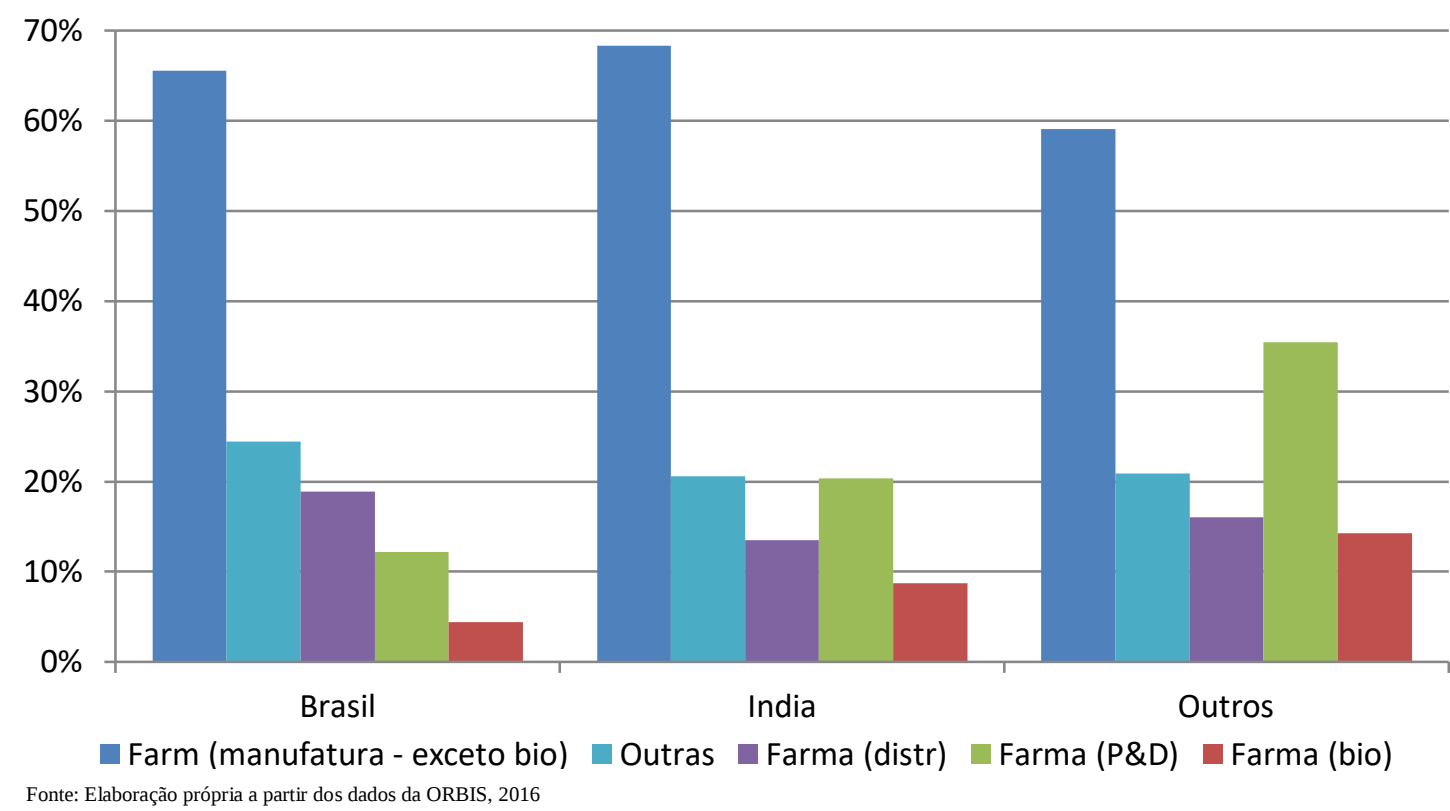

O gráfico 5 também apresenta informações para qualificar as empresas envolvidas em operações patrimoniais. Entretanto, analisa as competências das empresas adquiridas nas operações patrimoniais de acordo com a nacionalidade do comprador. Em geral, o mesmo padrão encontrado na análise que qualifica os alvos de acordo com sua nacionalidade se sustenta quando qualificamos o alvo de acordo com a nacionalidade do comprador, com o predomínio das operações cujo alvo detinha competências na produção de medicamentos (exceto biológicos). Também se observa um menor volume empresas adquiridas com competências em $P \& D$ e biotecnologia no Brasil e Índia em relação ao resto do mundo. O percentual de operações lideradas por empresas brasileiras e indianas cujo alvo detém competências na distribuição de medicamentos apresentou elevação. Apesar das diferenças serem sutis (por volta de 3,5 p.p.) o indicador parece suportar a ideia de que parte das aquisições das empresas destes países é destinada a obter mais canais de comercialização para seus produtos.

\section{Gráfico 5: Qualificação do alvo pela nacionalidade do comprador}

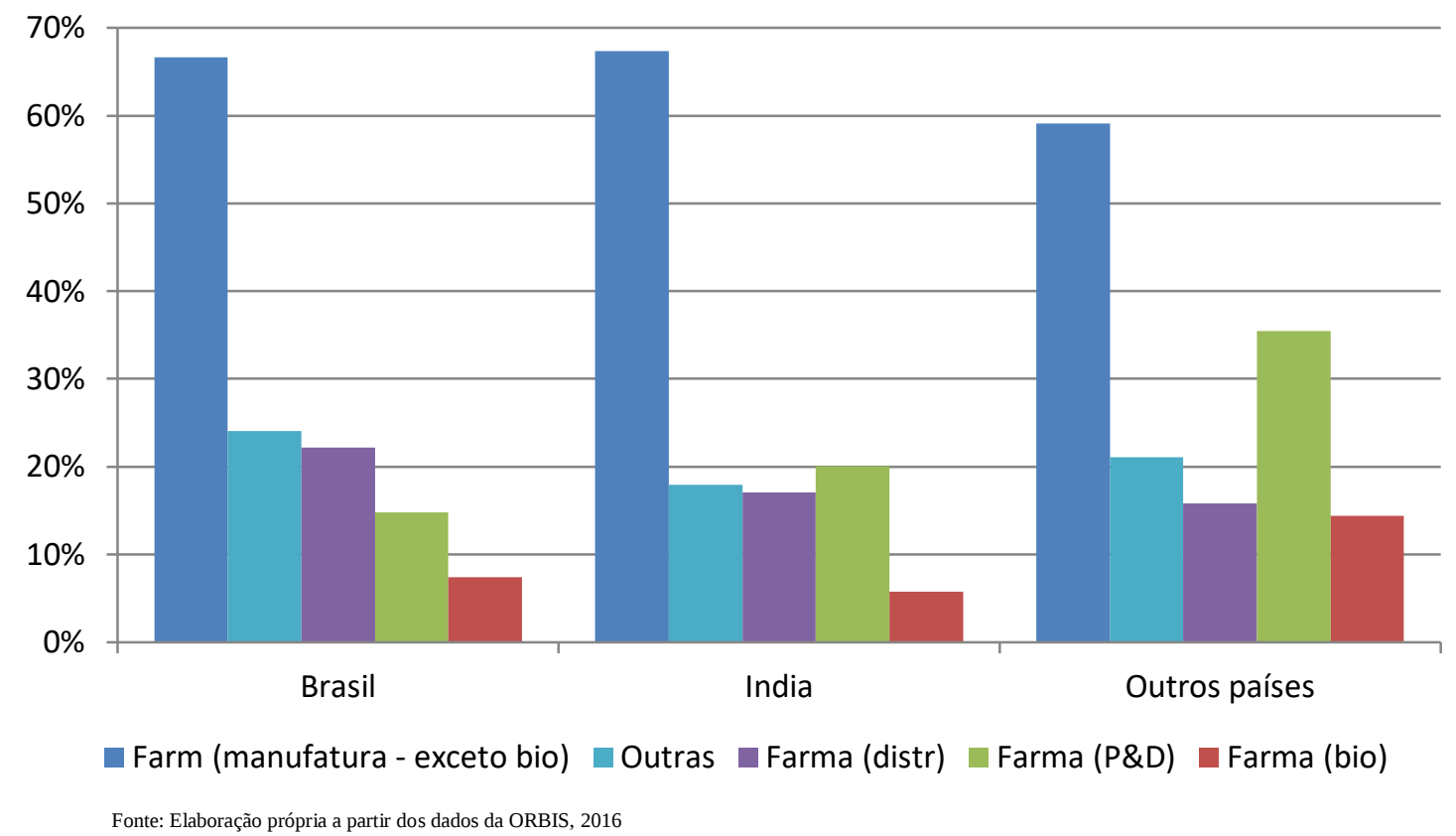


Os dados da Orbis também permitiram verificar para onde se dirigiram as aquisições de empresas indianas e brasileiras. O resultado é apresentado na figura 1, que mostra em verde os países para onde se direcionaram operações patrimoniais de empresas brasileiras, em vermelho para onde se direcionaram operações de empresas indianas $^{8}$ e em cinza países onde tanto empresas brasileiras e indianas realizaram operações. A espessura da linha está diretamente relacionada com o volume das operações em direção a estes países.

\section{Figura 1: Nacionalidade do alvo das operações realizadas por firmas indianas e brasileiras}

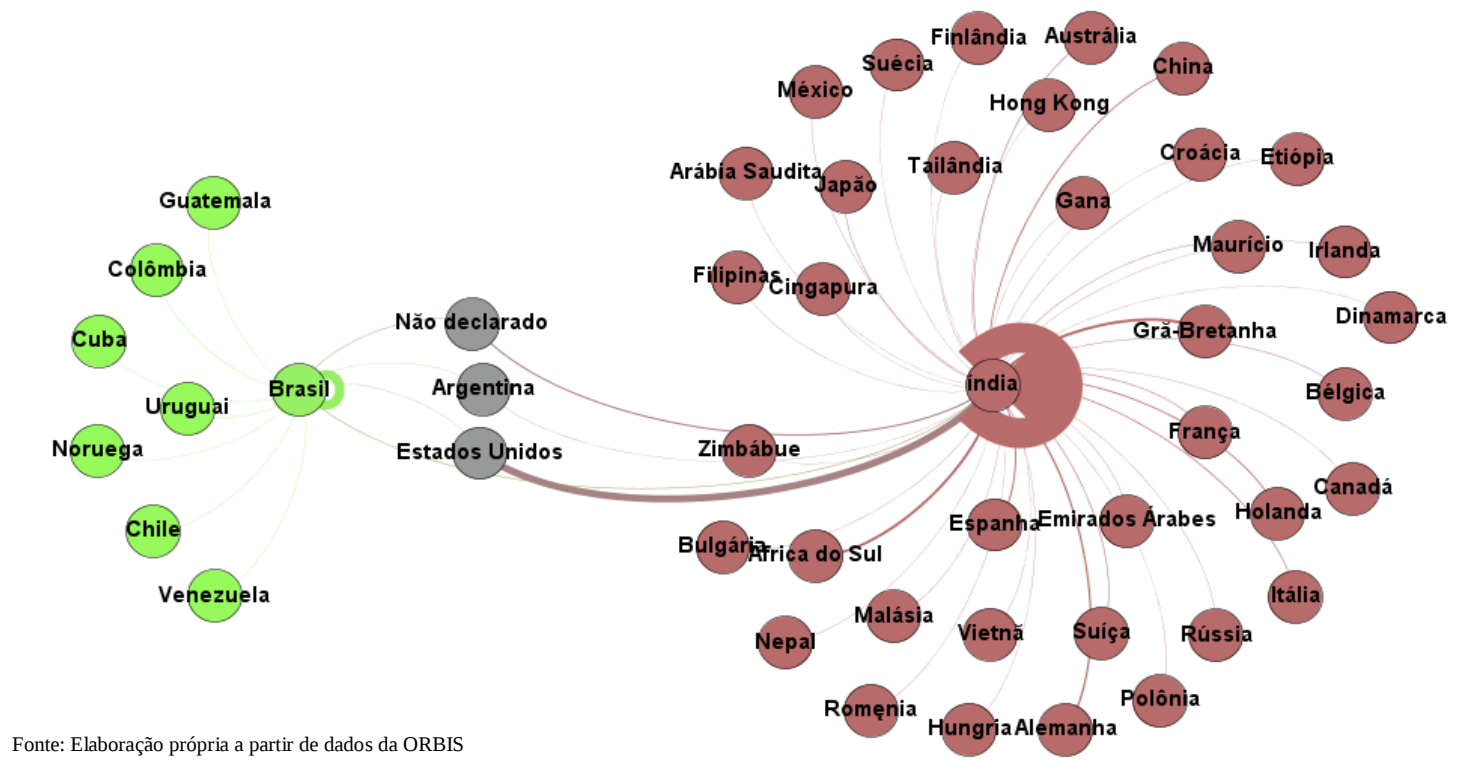

A figura mostra claramente que as empresas indianas realizaram operações em um número muito maior de países do que o Brasil. Além disso, nota-se que as empresas brasileiras limitaram sua área de influência aos países da América Latina, com exceção de operações realizadas com empresas da Noruega e dos EUA. As empresas indianas, ao contrário, foram muito além dos países ao seu redor, realizando operações com empresas de países em todos os continentes. Chama a atenção o maior volume de operações em direção aos países desenvolvidos, corroborando com a análise de Guennif e Ramani (2012) que apontou casos de operações patrimoniais e alianças estratégias entre empresas da Índia e países desenvolvidos, especialmente EUA, em busca do acúmulo de competências produtivas, inovativas e regulatórias.

Conclusão

O presente trabalho buscou explorar a hipótese de que as competências produtivas são um elemento importante para a geração de capacidade absorção nas firmas, que irá determinar a capacidade destas em identificar e explorar oportunidades de negócios via fusão, aquisição. Além disso, exploramos a ideia de que o ambiente econômico no qual as firmas estão inseridas também exerce influência sobre o movimento de fusões e aquisições. Para isso utilizamos as informações sobre operações patrimoniais na indústria farmacêutica e biotecnológica entre 1997-2015 contidas na base Orbis, com ênfase nas empresas brasileiras e indianas.

8 Empresas indianas também realizaram operações patrimoniais em direção a empresas brasileiras. 
As análises apresentadas são apenas exploratórias e, portanto, não são suficientes para afirmar as hipóteses levantadas durante o trabalho. No entanto, as análises apresentam evidências que corroboram com os diversos estudos de caso que apontam que as competências são um determinante importante nos processos de fusão e aquisição. Segundo os dados, as empresas indianas possuem um maior conjunto de competências em comparação com as brasileiras e apontam para uma maior e melhor inserção de empresas indianas no movimento de fusões e aquisições que ganhou força a partir de meados da década de 90. Desse modo, sugerimos a necessidade de aprofundarmos os estudos para avaliarmos de forma mais precisa as hipóteses levantadas.

\section{$\underline{\text { Referências bibliográficas }}$}

BASTOS, V. D., (2005). Inovação farmacêutica: padrão setorial e perspectivas para o caso brasileiro. Rio de Janeiro: BNDES Setorial.

CAPANEMA, Luciana Xavier de Lemos. A indústria farmacêutica brasileira e a atuação do BNDES. BNDES Setorial, Rio de Janeiro, n. 23, p. 193-215, 2006.

CLOODT, Myriam; HAGEDOORN, John; VAN KRANENBURG, Hans. Mergers and acquisitions: Their effect on the innovative performance of companies in high-tech industries. Research policy, v. 35, n. 5, p. 642-654, 2006.

COHEN, W. M.; LEVINTHAL, D. A. Absorptive Capacity: A New Perspective on Learning and Innovation. Administrative Science Quarterly, v. 35, n. 1, p. 128, mar. 1990.

COMANOR, William S.; SCHERER, Frederic M. Mergers and innovation in the pharmaceutical industry. Journal of health economics, v. 32, n. 1, p. 106-113, 2013.

DOSI, G.; TEECE, D. J. Organizational Competencies and the Boundaries of the Firm. In: Markets and Organization. Berlin, Heidelberg: Springer Berlin Heidelberg, 1998. p. 281-302.

EVALUATE PHARMA. World preview 2015, outlook to 2020, 2015. http://info.evaluategroup.com/rs/607-YGS-364/images/wp15.pdf; acessado em julho, 2015.

GADELHA, C. et al. A dinâmica do sistema produtivo da saúde: inovação e complexo econômico-industrial. 1. ed. Rio de Janeiro: Editoria Fiocruz, 2012. v. 01. 221p.

GUENNIFG, S.; RAMANI, S. V. Explaining divergence in catching-up in pharma between India and Brazil using the NSI framework. Research Policy, 41(2), 430-441, 2012

IMS Health for Healthcare Informatics Report. Global medicines use in 2020: outlook and implication. 2015. https://www.imshealth.com/en/thought-leadership/imsinstitute/reports/global-medicines-use-in-2020 \#ims-form. Accessed july 04, 2016

IOOTTY, M.; EBELING, F. Coerência corporativa e diversificação via fusões e aquisições: um exame para empresas líderes da indústria manufatureira norte-americana nos anos 90. Nova Economia, v. 17, n. 3, p. 475-509, dez. 2007.

JAMES, Andrew D. The strategic management of mergers and acquisitions in the pharmaceutical industry: Developing a resource-based perspective.Technology Analysis \& Strategic Management, v. 14, n. 3, p. 299-313, 2002. 
JENSEN, Michael C.; RUBACK, Richard S. The market for corporate control: The scientific evidence. Journal of Financial economics, v. 11, n. 1, p. 5-50, 1983

KLOECKNER, Gilberto de Oliveira. Fusões e aquisições: motivos e evidência empírica. Revista de Administração, v. 29, n. 1, p. 42-58, 1994.

KOENIG, Michael ED; MEZICK, Elizabeth M. Impact of mergers \& acquisitions on research productivity within the pharmaceutical industry.Scientometrics, v. 59, n. 1, p. 157-169, 2004.

KOSHIYAMA, Daniel Bohn; MARTINS, Marcilene. Fusões e aquisições e concentração industrial na indústria brasileira de agroquímicos, no período 199004. Ensaios FEE, v. 29, n. 1, 2008.

LAMATTINA, John L. The impact of mergers on pharmaceutical R\&D. Nature Reviews Drug Discovery, v. 10, n. 8, p. 559-560, 2011.

MALERBA, F. Learning by Firms and Incremental Technical Change. The Economic Journal, v. 102, n. 413, p. 845, jul. 1992.

NIGHTINGALE, P.; MAHDI, S..The evolution of pharmaceutical innovation.Knowledge accumulation and industry evolution: The case of pharmabiotech, p. 73-111, 2006.

VAN DIJK, Bureau. "Orbis database." Bureau Van Dijk Electronic Publishing(2016). Accessed march08, 2016.

PENROSE, Edith T. The theory of the growth of the firm. New York: Sharpe, 1959.

RAVENSCRAFT, David J.; SCHERER, Frederic M. Life after takeover. The Journal of Industrial Economics, p. 147-156, 1987.

VARGAS, M. A, Panorama Econômico do segmento de Biofármacos - proteínas recombinantes, 2015. Relatório para ABDI. 
Anexo 1: Tabelas com identificação dos códigos de atividade dos principais grupos

\begin{tabular}{|c|c|c|c|c|c|c|}
\hline & \multicolumn{5}{|c|}{ Farmacêuticas } & \multirow{2}{*}{ Financeiro } \\
\hline & Amplo & Manufatura (exceto bio) & Biofármacos & P\&D & Distribuição & \\
\hline 3254 & 1 & 1 & 0 & 0 & 0 & 0 \\
\hline 32541 & 1 & 1 & 0 & 0 & 0 & 0 \\
\hline 325411 & 1 & 1 & 0 & 0 & 0 & 0 \\
\hline 325412 & 1 & 1 & 0 & 0 & 0 & 0 \\
\hline 325413 & 1 & 1 & 0 & 0 & 0 & 0 \\
\hline 325414 & 1 & 0 & 1 & 0 & 0 & 0 \\
\hline 424210 & 1 & 0 & 0 & 0 & 1 & 0 \\
\hline 446110 & 1 & 0 & 0 & 0 & 1 & 0 \\
\hline 5417 & 1 & 0 & 0 & 1 & 0 & 0 \\
\hline 54171 & 1 & 0 & 0 & 1 & 0 & 0 \\
\hline 541711 & 1 & 0 & 1 & 1 & 0 & 0 \\
\hline 541712 & 1 & 0 & & 1 & 0 & 0 \\
\hline
\end{tabular}

\begin{tabular}{|c|c|c|c|c|c|c|}
\hline 521110 & 0 & 0 & 0 & 0 & 0 & 1 \\
\hline 522110 & 0 & 0 & 0 & 0 & 0 & 1 \\
\hline 522120 & 0 & 0 & 0 & 0 & 0 & 1 \\
\hline 522190 & 0 & 0 & 0 & 0 & 0 & 1 \\
\hline 5222 & 0 & 0 & 0 & 0 & 0 & 1 \\
\hline 522210 & 0 & 0 & 0 & 0 & 0 & 1 \\
\hline 522220 & 0 & 0 & 0 & 0 & 0 & 1 \\
\hline 522291 & 0 & 0 & 0 & 0 & 0 & 1 \\
\hline 522292 & 0 & 0 & 0 & 0 & 0 & 1 \\
\hline 522293 & 0 & 0 & 0 & 0 & 0 & 1 \\
\hline 522298 & 0 & 0 & 0 & 0 & 0 & 1 \\
\hline 522310 & 0 & 0 & 0 & 0 & 0 & 1 \\
\hline 5231 & 0 & 0 & 0 & 0 & 0 & 1 \\
\hline 523110 & 0 & 0 & 0 & 0 & 0 & 1 \\
\hline 523120 & 0 & 0 & 0 & 0 & 0 & 1 \\
\hline 5239 & 0 & 0 & 0 & 0 & 0 & 1 \\
\hline 523910 & 0 & 0 & 0 & 0 & 0 & 1 \\
\hline 523920 & 0 & 0 & 0 & 0 & 0 & 1 \\
\hline 523930 & 0 & 0 & 0 & 0 & 0 & 1 \\
\hline 523991 & 0 & 0 & 0 & 0 & 0 & 1 \\
\hline 523999 & 0 & 0 & 0 & 0 & 0 & 1 \\
\hline 524113 & 0 & 0 & 0 & 0 & 0 & 1 \\
\hline 524114 & 0 & 0 & 0 & 0 & 0 & 1 \\
\hline 524126 & 0 & 0 & 0 & 0 & 0 & 1 \\
\hline 524210 & 0 & 0 & 0 & 0 & 0 & 1 \\
\hline 525110 & 0 & 0 & 0 & 0 & 0 & 1 \\
\hline 525120 & 0 & 0 & 0 & 0 & 0 & 1 \\
\hline 5259 & 0 & 0 & 0 & 0 & 0 & 1 \\
\hline 525910 & 0 & 0 & 0 & & & 1 \\
\hline 525920 & 0 & 0 & 0 & 0 & 0 & \\
\hline 525990 & 0 & 0 & 0 & 0 & 0 & 0 \\
\hline
\end{tabular}

